East African Medical Journal Vol. 80 No. 10 October 2003

HISTOPATHOLOGIC PATTERN OF THYROID DISEASE

B. Tsegaye, MD, Ethiopian Health and Nutrition Research Institute, P.O. Box 1242 or 5654, Addis Ababa, Ethiopia and W. Ergete, MD, Department of Pathology, Faculty

of Medicine, Addis Ababa University, P.O. Box 9086, Addis Ababa, Ethiopia

Request for reprints to: Dr. B. Tsegaye, Ethiopian Health and Nutrition Research Institute P.O. Box 1242, Addis Ababa, Ethiopia

\title{
HISTOPATHOLOGIC PATTERN OF THYROID DISEASE
}

\section{B. TSEGAYE and W. ERGETE}

\begin{abstract}
Background: Diseases of the thyroid are manifested by alteration in hormone secretion, enlargement of the thyroid gland (goiter), or both. The principal diseases of the thyroid gland are goiter (diffuse or nodular), hypo or hyperthyroidism, thyroiditis and neoplasms. The incidence and prevalence of these thyroid diseases in a given community are variable depending on various factors. Simple (non-toxic) goiter is extremely common throughout the world and is most prevalent in mountainous areas. The reported prevalance of goiter in Ethiopia varies between $18 \%$ and $30 \%$.

Objective: To review the histopathologic patterns of thyroid disease and their relationship with age and sex over a five year period.

Setting: Tikur Anbessa teaching and referral hospital, Department of Pathology, Faculty of Medicine, Addis Ababa University.

Methods: Retrospective analysis of five years biopsy material from patients with thyroid disease.

Results: Seven hundred and eighty consecutive patients with thyroid disease were included in the study. Six hundred and $\operatorname{sixty}(79 \%)$ were found to be non-neoplastic and $164(21 \%)$ were neoplastic. Nodular colloid goiter (NCG) were found in 600 (76.9\%) cases. Adenoma, carcinoma and thyroiditis accounted for $100(12.8 \%), 64(8.2 \%)$ and $16(2.1 \%)$ cases respectively. Female to male ratio was $4.5: 1$. Eighty five point seven per cent of the thyroid diseases were found in the age group 20-59 years.

Conclusion: Nodular colloid goiter is the most prevalent thyroid disease. Papillary carcinoma is the most frequent cancer seen in this series. Appropriate measures should be taken to reduce the iodine deficiency states in the diet to alleviate the social and medical consequences of the NCG. Similary clinical evaluation of goiter should be thorough, and use all means especially histopathologic study of the specimens to arrive at a definitive diagnosis as thyroid carcinoma is not uncommon.
\end{abstract}

\section{INTRODUCTION}

There are many conditions in which the thyroid gland is affected. These diseases of the thyroid are manifested by alterations in hormone secretion, enlargement of the thyroid gland (goiter) or both(1). The principal diseases of the thyroid gland are goiter (diffuse or nodular), hypothyroidism, hyperthyroidism, thyroiditis and neoplasms. The incidence and prevalence of these thyroid diseases in a given community are variable depending on various factors(2). Simple (non-toxic) goiter is extremely common throughout the world and is thought to affect more than 200 million individuals. It is most prevalent in mountainous areas but also occurs in non-mountainous areas remote from sea. Iodine deficiency is the major cause but goitrogens as well are incriminated. Depending on the severity of iodine defiency, goiter may appear in early childhood but usually peaks at about puberty or soon after then, affecting more females than males(3).

Neoplastic diseases are also seen in the thyroid. Adenoma is the commonest benign tumour of the thyroid.
With few exceptions thyroid carcinoma is the malignant neoplasm of the thyroid, which arises from follicur epithelium. Thyroid carcinoma causes about 7000 deaths annualy in the United States with a 2.3:1 female to male ratio(3). The cause of thyroid cancer is not well known but observations have proved exposure to radiation to incur great risk, similarly increases the incidence of follicular carcinoma is increased in areas of iodine deficiency, suggesting that in some cases nodular colloid goiter may predispose to the development of neoplasms $(3,4)$. Other thyroid disease entities like thyrotoxicosis, thyroiditis and hypothyroidism are not uncommon(2,3,5-7). Diagnosis of a thyroid disease needs a thorough clinical examination in addition with assessment of the hormone secretion activities of the gland and its morphology. Histopathologic examination is one of the latter, which gives a definitive diagnosis(2).

The prevalence of goiter in different geographic areas of Ethiopia is also high. A cross-sectional survey in Sekotta district showed the overall prevalence of goiter to be $22.8 \%(8)$. Similary a study carried out to detect the 
prevalance of goiter in school children and household members has shown the prevalence of goiter to be $30.6 \%$ and $18.7 \%$ respectively(9).

Thus the purpose of this retrospective study was to review the histopathologic pattern of thyroid disease and their relationship with age and sex as seen in the Department of Pathology, Faculty of Medicine, Addis Ababa University (FMAAU) over a five period (19941998).

\section{MATERIALS AND METHODS}

A Retrospective review of records has been undertaken in patients with thyroid. Diagnosis of the diseases were reached by histopathological examination of thyroid specimens submitted to the Department of pathology, Faculty of Medicine, Addis Ababa University. This department handles the majority of the histopathological examinations for the whole country. All patients who had undergone histopathologic examination for thyroid diseases between January 1994 and December 1998 were included in this study. All biopsies specimens were formalin fixed and paraffin embedded sections and stained using Haematoxylin and Eosin (H\&E). The reports, slides and blocks were kept in the department archives. All sections were diagnosed and reported by pathologists. Information collected included patients's age, sex and the histopathologic diagnosis. The slides were not retrieved for review, the index diagnosis was accepted as a final diagnosis. The thyroid diseases were classified on histological grounds into: nodular colloid goiter, including both colloid and adenomatous goiter, adenoma (both follicular and hurthle cell type), all types of thyroiditis and carcinoma including all subtypes that is follicular, papillary, medullary and anaplastic carcinomas. Twelve report forms, which were incomplete for the above variable were excluded from the study. Duplication were excluded as much as possible. The available data were analysed by using simple descriptive and Epi info 6.04 statistical package.

\section{RESULTS}

A total of 21,696 surgical operations were submitted for histopathological examination during the study period, out of these 792 (3.6\%) were thyroid specimens. Nodular colloid goiter accounted for $600(76.9 \%)$ cases. Thyroid neoplasms were encountered in $164(21 \%)$ cases only. The benign tumour i.e., adenoma were seen in 100 (12.8\%) cases and thyroid carcinoma in $64(8.2 \%)$ cases. Thyroiditis constituted $16(2.1 \%)$ of the cases (Table 1$)$. The majority of the cases; that is $85.7 \%$ of the thyroid diseases in this study were seen in the age group 20-59 years, the young age group 0-19 years and the elderly group above 60 years constituted $9.8 \%$ and $4.3 \%$ respectively. The age distribution of the specific thyroid disease entities as shown in Table 2. Females were most commonly affected by thyroid diseases $(80.5 \%)$ than males (19.5\%). Table 3 shows specific thyroid disease entities in relation with sex.

The morphological subdivision of the 64 thyroid carcinomas showed $76.6 \%$ of papillary, $15.6 \%$ follicular, $6.3 \%$ anaplastic, and $1.5 \%$ medullary carcinoma (Table 4). There were four Hashimoto's, three each sub-acute and lymphocytic, one Reidel's and five thyroiditis without specification.

Table 1

Histopathological patterns of thyroid diseases encountered in 780 thyroidectomy specimens examined

\begin{tabular}{lcc}
\hline Histological disease & No. & $\%$ \\
\hline Nodular colloid goiter & 600 & 76.9 \\
Thyroid adenoma & 100 & 12.8 \\
Thyroid carcinoma & 64 & 8.2 \\
Thyroiditis & 16 & 2.1 \\
\hline Total & 780 & 100 \\
\hline
\end{tabular}

Table 2

Distribution of the histological thyroid disease in relation with age

\begin{tabular}{lccccc}
\hline Age in years & NCG@ $(\%)$ & $\begin{array}{c}\text { Histological thyroid diseases } \\
\text { Adenoma } \\
\text { No. }(\%)\end{array}$ & $\begin{array}{c}\text { Carcinoma } \\
\text { No. }(\%)\end{array}$ & $\begin{array}{c}\text { Thyroiditis } \\
\text { No. }(\%)\end{array}$ & $\begin{array}{c}\text { Total } \\
\text { No. }(\%)\end{array}$ \\
\hline $0-9$ & - & - & $1(1.5)$ & - & $1(0.1)$ \\
$10-19$ & $60(10)^{*}$ & $10(10)$ & $4(6.3)$ & $2(12.5)$ & $76(9.7)$ \\
$20-29$ & $179(29.8)$ & $31(31)$ & $21(32.8)$ & $3(18.7)$ & $234(30)$ \\
$30-39$ & $193(32.2)$ & $27(27)$ & $14(21.8)$ & $6(37.5)$ & $240(30.7)$ \\
$40-49$ & $103(17.2)$ & $22(22)$ & $7(11)$ & $3(18.7)$ & $135(17.3)$ \\
$50-59$ & $40(6.6)$ & $7(7)$ & $12(18.7)$ & $1(6.2)$ & $60(7.7)$ \\
$60-69$ & $22(3.6)$ & $3(3)$ & $4(6.3)$ & $1(6.2)$ & $30(3.8)$ \\
$70-79$ & $3(0.5)$ & - & $1(1.5)$ & - & $4(0.5)$ \\
\hline Total & 600 & 100 & 64 & 16 & 780 \\
\hline
\end{tabular}

@ Nodular colloid goiter 
Table 3

Distribution of the histologic thyroid diseases in relation with sex

\begin{tabular}{|c|c|c|c|c|c|}
\hline \multirow[t]{3}{*}{ Sex } & \multicolumn{3}{|c|}{ Histology of thyroid diseases } & \multicolumn{2}{|l|}{ Total } \\
\hline & NCG@(\%) & Adenoma & Carcinoma $(\%)$ & Thyroiditis & No. $(\%)$ \\
\hline & & No. $(\%)$ & No. $(\%)$ & No. $(\%)$ & \\
\hline Female & $492(82)^{*}$ & $80(80)$ & $42(65.6)$ & $14(87.5)$ & $628(80.5)$ \\
\hline Male & $108(18)$ & $20(20)$ & $22(34.4)$ & $2(12.5)$ & $152(19.5)$ \\
\hline Total & 600 & 100 & 64 & 16 & 780 \\
\hline
\end{tabular}

@Nodular colloid goiter

Table 4

Morphologic subdivisions of the 64 thyroid carcinomas

\begin{tabular}{lcc}
\hline Thyroid carcinomas & No. & $\%$ \\
\hline Papillary & 49 & 76.6 \\
Follicular & 10 & 15.6 \\
Anaplastic & 4 & 6.3 \\
Medullary & 1 & 1.5 \\
\hline Total & 64 & 100 \\
\hline
\end{tabular}

\section{DISCUSSION}

Nodular colloid goiter (NCG) is the commonest disease as it was seen in $600(76.9 \%)$ of the cases in this study. This is higher than the $47.7 \%$ reported in a retrospective histopathological study done on 575 histopathological reports over a five year period(5). This might be due to a difference in indications for the thyroidectomy and the availability of histopathological laboratories. It could as well be due to a real difference in the magnitude of the disease. The higher rate of NCG in our study might be as a result of the effect of the study area in consideration of the histopathological service rendered for the major part of the country is within this department. However it was in agreement with a retrospective analysis of 1494 thyroid cases seen at the thyroid clinic of Kenyatta National Hospital by Gitau who reported a $75.2 \%(6)$. The degree of thyroid enlargement is proportional to the level and duration of thyroid hormone deficiency. In most cases the increased thyroid mass eventually achieves euthyroid State. In the form known as endemic goiter, the incidence of goiter in a particular geographic local area is more than $10 \%$ of the population. It is extremely common throughout the world and most prevalent in mountainous areas. A deficient intake of iodine is the dominant cause of the disease. Lack of iodine leads to disease synthesis of thyroid hormones and a compensatory increase in Thyroid Stimulating Hormone (TSH) leading to follicular cell hypertrophy and hyperplasia and in the ensuing period goitrous enlargement. The other causative influences are goitrogens which can be dietary substances, drugs, minerals, etc. They block thyroid hormone synthesis which lead to goitrous enlargement. The other form known as sporadic goiter is much less common than the endemic variety. The cause of this condition is rarely evident and a number of influences act in concert with minimal iodine deficiency, increased demand for thyroid hormone, biosynthetic defects in hormone synthesis etc.

Females $(80.5 \%)$ preponderance of the thyroid diseases over males (19.5\%) observed in this study making a female:male ratio of $4.5: 1$. This was in agreement with studies done in Kenya $(5,6)$, Ethiopia $(8,9)$ and other observations(1-3). The thyroid disease in particular NCG was seen in almost all age groups and its high prevalence in the age group $20-59$ years $(85.8 \%)$ was similar to other observations $(2,3)$. The $30.6 \%$ prevalence rate of goiter reported by Wolde-gebriel et al(9) in school children was higher than the $10 \%$ reported in this study. This may be a consequence of the nature of the study and the geographic location of the study area.

Thyroid neoplasms (21\%) were the second most common histological diseases in our study analogous to Kungu (5). Nonetheless the rate in this study is lower than his report of $43 \%$. This may be partly explained by the difference in indications for the thyroidectomy in the two areas i.e., medical or social cosmetic reasons. The prevalence of adenoma in our study was consistent with the study made by Gitau(6) but still lower than the report by Kungu(5). The sex and age distribution of the adenoma seen in our study was consistent with most other reports(2,3). Carcinomas of the thyroid are relatively uncommon. Most cases occur in adults although some forms particularly papillary carcinoma may be present in childhood. A female preponderance has been noted among patients developing thyroid carcinoma in the early and middle adult years. Most thyroid carcinomas are well differentiated types. The major risk factor predisposing to thyroid cancer is exposure to ionizing radiation, particularly during the first two decades of life. Certain thyroid diseases such as nodular colloid goiter and autoimmune thyroid diseases (Hashimoto's thyroiditis) have been implicated as predisposing factors.

Unlike the belief that thyroid carcinoma is a rare disease(3), it was seen in $64(8.2 \%)$ cases in our study. This is however lower than the $23.3 \%$ reported by 
Kungu(5). The sex and age distribution of the thyroid carcinoma seen in our study was consistent with other observations $(2,3,5)$. There were four histological variants of thyroid carcinoma as shown in Table 4. Each had its own clinical and biological significance. Papillary carcinoma was found to account for $(76.6 \%)$ of the carcinomas in our series followed by follicular carcinoma $(15.6 \%)$. This is in keeping with most other observations(2,3). But not with that of Kungu(5) and Wahner et al(4) which showed a higher prevalence of follicular carcinoma. But this was not evident in this study as it was observed follicular carcinoma contributed for a small number of cases.

The other histological thyroid disease encountered in our study was thyroiditis $(2.1 \%)$. This low prevalence rate was in keeping with a report made by Kungu (3\%)(5) and Gitau (1\%) (8). The female sex predilection (87.5\%) over males (12.5\%) and a predominance of the problem in the age group 20-59 years and was also seen by other studies(2,3). Although other thyroid diseases like thyrotoxicosis and hyperthyroidism were not described in our review and as well not addressed in most other studies done in Ethiopia, they are not uncommon. A prospective study of 110 Ethiopians with thyrotoxicosis in a weekly clinic of Tikur Anbessa teaching hospital by Mengistu(7) showed an incidence of 22 patients per year indicating that the disease is not rare as it was previously thought to be or even reported by Lester et al(10) after analysis of hospital admissions in Addis Ababa Ethiopia where thyrotoxicosis was reported to have a low prevalence rate that ranged between $1.3-3 \%$.

In summary this retrospective histopathological study showed that nodular colloid goiter is the commonest histological disease. Studies have also proved colloid goiter to be a result of iodine deficiency and iodine supplement was found to decrease the prevalence of goiter. Hence we recommend that iodine supplement to be effected to reduce the prevalence of this disease. This will help to reduce the resources spent on managing individual goiter cases besides alleviating the social impact of goiter. This study also revealed that neoplasms of the thyroid to be the second most common histologic diseases, especially the benign tumour adenoma and thyroid carcinoma. Thyroid carcinoma (papillary carcinoma in particular), though uncommon is not a rare disease in our area. We recommend clinical evaluation of any enlarged thyroid to be thorough and not be overshadowed by the prevalent nodular goiter, rather it should always raise the possibility of thyroid neoplasm particularly thyroid carcinoma and all possible endeavor must be made to arrive at a definite diagnosis. Unlike the usual observation, the follicular carcinoma was not a common histologic type of carcinoma in this study.

\section{ACKNOWLEDGEMENT}

The authors would like to thank all the staff members of the Department of Pathology, Faculty of Medicine, Addis Ababa University for their assistance during the data collection.

\section{REFERENCES}

1. Wartofsky, L. Diseases of the thyroid in Fauci, A.S., Braunwald, E. et al ed: Principles of internal medicine 14th edition. 1998; 2: 2012-2035.

2. Bayliss Ris. Thyroid disease. The fact, Oxford University press, New York, Toronto, 1982.

3. Cotran, R.S. Kumar, V. and Robins, S.I. The thyroid in Robins, SI. ed. Pathological bases of disease. Philadelphia W. B. Saunders Company 5th edition 1994.

4. Wahner H.W. Luello. C. et al. Thyroid carcinoma in an endemic area, Cali., Colombia. Amer. J. Med. 1966; 40:58

5. Kungu, A. The pattern of the thyroid disease in Kenya. East. Afr. Med. J. 1974; 51:449-466.

6. Gitau, W. Analysis of thyroid diseases seen at Kenyatta National hospital. East. Afr. Med. J. 1975; 53:564-570.

7. Mengistu, M. A prospective study of 110 Ethiopians with thryrotoxicosis. East. Afr. Med. J. 1992; 69:515-519.

8. Mekones, E. Prevalence of goiter in Sekotta district, Ethiopia. East. Afr. Med. J. 1996; 73:264-267.

9. Wolde-gebriel, Z., Demeke, T. West, C.E. and Haar, F.U.D. Goiter in Ethipia: in Wolde Gebriel Z. ed Micronutrient deficiencies in Ethiopia and their interrelationship Wageningn, Grafisch Service Centrum, LUW 1992; 41-56.

10. Lester, F.T. and Tsega, E. The pattern of adult medical admission in Addis Ababa Ethiopia. East. Afr. Med. J. 1976; 53:620-634. 